\title{
REDESCRIÇÃO DE ARTHURELLA ALBUQUERQUE COM CONSIDERAÇÓES SOBRE SUA POSIÇÃO SISTEMÁTICA E REDESCRIÇÃO DO PUPARIO DE A. NUDISETA ALBUQUERQUE (DIPTERA, MUSCIDAE)
}

\author{
Paulo Francisco de Araújo ${ }^{1}$ \\ Márcia Souto Couri ${ }^{1,2}$
}

\begin{abstract}
REDESCRIPTION OF ARTHURELLA ALBUQUERQUE WITH CONSIDERATIONS ON ITS SYSTEMATIC POSITION AND REDESCRIPTION OF THE PUPARIUM OF A. NUDISETA ALBUQUERQUE (DIPTERA, MUSCIDAE). Arthurella Albuquerque, 1954 is redescribed and its systematic position is discussed. The puparium of $\mathbf{A}$. nudiseta Albuquerque, 1954 is also redescribed and illustrated.
\end{abstract}

KEY WORDS. Arthurella, Muscidae, redescription, systematic position

ALBUQUERQUE (1954) descreveu o gênero monotípico Arthurella, posicionando-o entre os Phaoninae. Aproximou-o de Steinella Malloch, 1921, e apresentou uma chave para facilitar a segregação dos mesmos. A. nudiseta Albuquerque, 1954 foi designada como espécie tipo, com base em machos (no trabalho original, página 151, consta por engano "fêmea") provenientes do Chile. LOPES (1984) descreveu a fêmea e o pupário desta espécie, com base em outro material também proveniente do Chile; considerando-o um Cyrtoneurininae, seguindo PONT (1972). LOPES \& COURI (1989) incluíram o gênero Arthurella em uma chave para segregação dos Cyrtoneurininae neotrópicos. Com o objetivo de fundamentar o posicionamento de Arthurella entre os Muscidae, a redescrição do ovipositor e a descrição da probóscide são apresentadas, para permitir a utilização da metodologia descrita em CARVALHO (1989a).

\section{MATERIAL E MÉTODOS}

Os pupários, em função da forte esclerotinização da região apical, foram tratados em hidróxido de potássio a $10 \%$ em banho-maria por trinta minutos e a seguir a frio por vinte e quatro horas. A visualização das fendas espiraculares só foi possível após mais 72 horas na mesma solução a frio. O material estudado foi acondicionado em frascos de vidro com glicerina e se encontra depositado na Coleção de Diptera do Museu Nacional, Rio de Janeiro.

1) Museu Nacional, Universidade Federal do Rio de Janeiro, Quinta da Boa Vista, São Cristóvão, 20940-040 Rio de Janeiro, Rio de Janeiro, Brasil.

2) Bolsista do CNPq. 
A terminologia empregada para a descrição morfológica do pupário e para o adulto é a mesma adotada por SKIDMORE (1985) e CARVALHO (1989b), respectivamente.

\section{Arthurella Albuquerque}

Figs 1-11

Arthurella Albuquerque, 1954: 151 (desc.); Pont, 1972: 57 (cat.); Lopes, 1984:335 (desc. fêmea); Lopes \& Couri, 1989: 2 (chave).

Descrição. Olhos curtos e esparsamente ciliados, holóptico; arista com diminutos cílios, terceiro artículo antenal dilatado e arredondado na base, cerdas acrosticais $2: 1$; pré-alar fraca, porém nítida e mais desenvolvida nas fêmeas; notopleura com poucos cílios próximos à base da notopleural posterior; cerdas catepisternais $2: 2$, três cerdas pró-epimerais longas e semelhantes entre si. Veia $\mathrm{R}_{1}$ com cílios no $1 / 3$ médio da face dorsal, $\mathrm{R}_{4+5}$ ciliada nas faces dorsal e ventral da base até a metade da distância entre a bifurcação e a r-m; espiráculo anterior alongado; tíbia II na face posterior com quatro cerdas; tíbia III com uma posterodorsal pré-apical. Macho: espiráculo posterior ovalado; primeiro esternito nú. Fêmea: verticais externas e interna longas semelhantes entre si, as últimas divergentes; cerdas interfrontais cruzadas presentes. Probóscide: (Fig. 1) com clípeo sem ponta; haustelo na região anterior com esclerotinização ciliada, arco do fulcro com leve curvatura inferior, dentes prestomatais não desenvolvidos, palpo falciforme. Ovipositor (Figs 2 e 3): tergitos alongados, tergito VI em forma de âncora; esternito VI e VII inteiros; microtríquias nas membranas intersegmentares VI-VII e VII-VIII, cercos longos com cerdas somente na face externa, epiprocto triangular e hipoprocto arredondado com cerdas fortes e curtas; espermatecas alongadas (Fig. 4) em número de três. ginal).

Espécie tipo: Arthurella nudiseta Albuquerque, 1954 (designação ori-

Discussão. Analisando os caracteres do gênero e, com base em CARVALHO (1989a), posicionamos Arthurella entre os Azellinae, Reinwardtiini, principalmente pelas apomorfias: haustelo na região anterior com esclerotinização ciliada e tergito VI esclerotinizado em forma de âncora. Os caracteres do pupário como fendas espiraculares quase retas e convergentes para o botão espiracular também posicionam este gênero em Reinwardtiinae sensu (SKIDMORE, 1985).

\section{Arthurella nudiseta Albuquerque, 1954}

Arthurella nudiseta Albuquerque, 1954:151 (desc. macho, nec fêmea); Pont, 1972: 57 (cat.); Lopes, 1984: 334-337 (desc. fêmea).

Pupário. Aspecto geral como nas figuras 5 e 6; coloração castanha, último segmento mais escuro, espiráculo posterior negro fortemente esclerotinizado, segmentos na face dorsal (Fig. 7) com fileiras irregulares de espinhos fracos e fortes e, na face ventral (Fig. 8) com fileiras de espinhos mais alargadas 


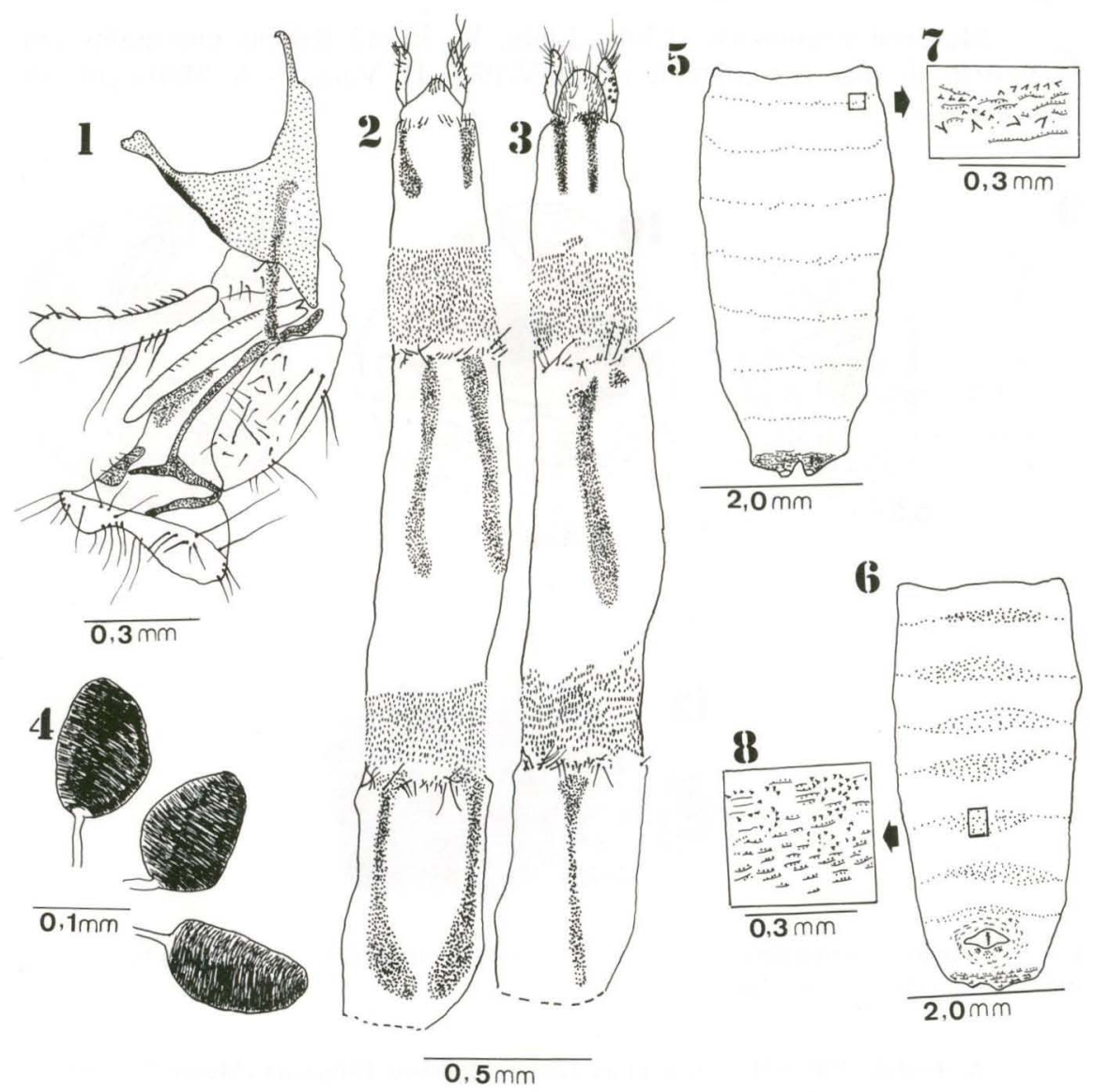

Figs 1-8. Arthurella nudiseta. (1) Probóscidae da fêmea em vista lateral; (2) Genitália da fêmea, ovipositor em vista dorsal e (3) em vista ventral; (4) espermatecas; (5) aspecto geral do pupário, vista dorsal e (6) vista ventral; (7) detalhes dos segmentos na face dorsal do pupário e (8) na face ventral.

medianamente; região peri-anal (Fig. 9) ornamentada com espinhos fortes e fracos em toda sua extensão, placa anal ornamentada com espinhos fracos semelhantes aos da região peri-anal, fenda anal ocupando quase todo o comprimento mediano da placa, papilas subanais e papila pós-anal com diâmetro semelhante; espiráculo posterior (Fig. 10) em uma elevação mediana, ornamentado, ao redor, com espinhos curtos e largos e estrias irregulares mais esclerotinizadas, fendas espiraculares alongadas (Fig. 11)

Considerações. Os pupários de Arthurella nudiseta estudados estão completamente cobertos por sedimentos (grãos de areia) como na figura 12, este hábito é encontrado em muitas espécies de Reinwardtiinae (SKDIMORE, 
1985).

Material examinado: Chile, Lluta, K. 30, 12 fêmeas emergidas em 18/V/1976, de material coletado em 10/V/1976, H. Vargas - A. Matta col., ex Agaricaceae.
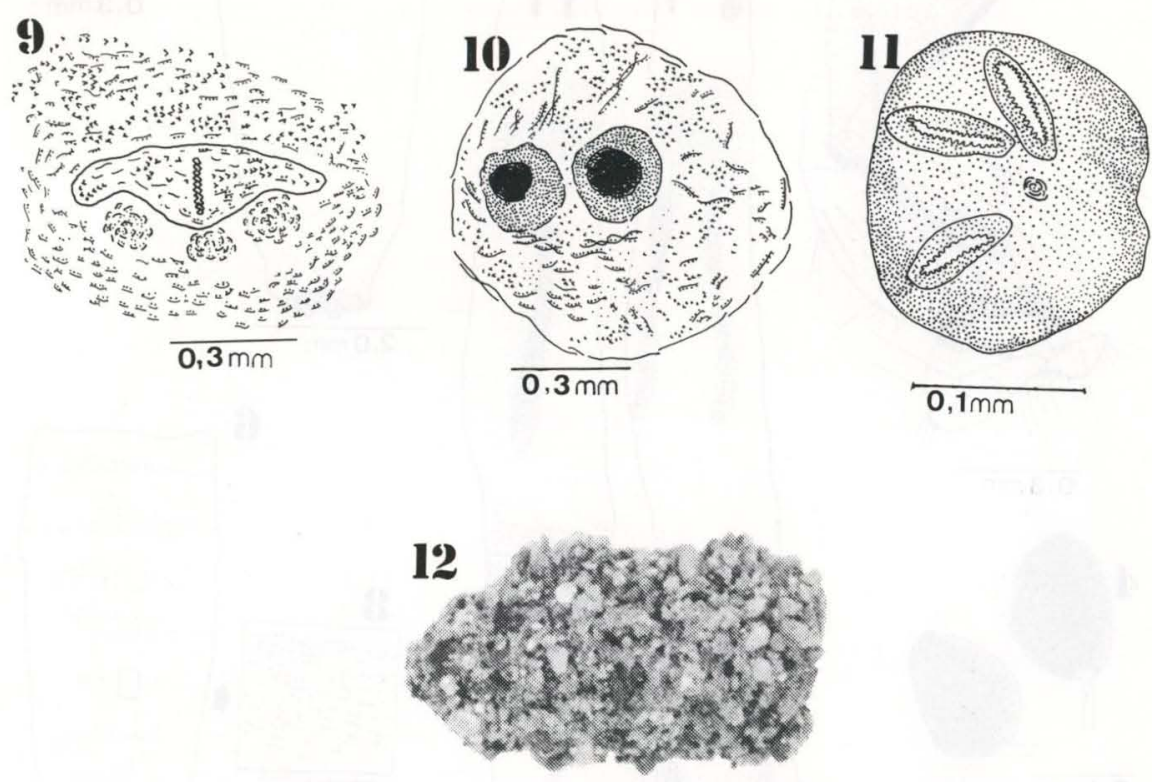

Figs 9-12. Arthurella nudiseta. (9) Região peri-anal; (10) espiráculo posterior; (11) fendas espiraculares do espiráculo posterior; (12) Pupário.

AGRADECIMENTOS. Aos Profs Denise Medeiros Pamplona (Museu Nacional) e Claudio José Barros de Carvalho (Universidade Federal do Paraná) pela leitura crítica do manuscrito e ao Prof. Sérgio Fragoso (EMBRAPA) pela fotografia do pupário.

\section{REFERÊNCIAS BIBLIOGRÁFICAS}

ALBUQUERQUE, D.O. 1954. Sobre um gênero novo de Phaoninae do Chile e notas sobre Steinella fuscinervis (Macquart) (Diptera - Muscidae). Revta bras. Ent. 1: 151-158.

CARVALHO, C.J.B. DE. 1989a. Muscidae (Diptera): uma proposta de análise cladística. Revta bras. Zool. 6 (4): 627-648.

— 1989 b. Revisão das espécies e posição sistemática de Palpibracus Rondani (Diptera, Muscidae). Revta bras. Zool. 6 (12): 325-373.

LOPES, S.M. 1984. Descrição de uma fêmea de Arthurella nudiseta Albuquerque, 1954 (Diptera - Muscidae - Cyrtoneurininae) coletada em Agaricaceae (Fungi). Rev. Brasil. Biol. 44 (3): 335-337. 
LOPES, S.M. \& M.S. COURI. 1989. Key to the identification of neotropical genera of Cyrtoneurininae (Diptera - Muscidae). Bol. Mus. Nac., N.S., Zool., Rio de Janeiro, 332: 1-6.

PONT, A.C. 1972. Family Muscidae. In: A catalogue of the Diptera of Americas South of the United States 97. São Paulo, Museu de Zoologia, Universidade de São Paulo, 111p.

SKIDMORE, P. 1985. The biology of Muscidae of world. Dordrecht, Junk Publishers, XIV + 550p.

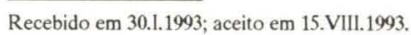

